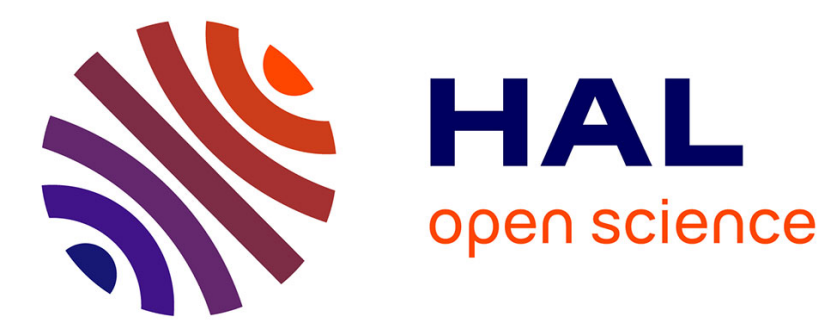

\title{
Geometrical Specification Model for Gear - Expression, Metrology and Analysis
}

Jean-Yves Dantan, Julien Bruyere, Cyrille Baudouin, Luc Mathieu

\section{To cite this version:}

Jean-Yves Dantan, Julien Bruyere, Cyrille Baudouin, Luc Mathieu. Geometrical Specification Model for Gear - Expression, Metrology and Analysis. CIRP Annals - Manufacturing Technology, 2007, 56 (1), p. 517-520. 10.1016/j.cirp.2007.05.123 . hal-00750731

\section{HAL Id: hal-00750731 \\ https://hal.science/hal-00750731}

Submitted on 12 Nov 2012

HAL is a multi-disciplinary open access archive for the deposit and dissemination of scientific research documents, whether they are published or not. The documents may come from teaching and research institutions in France or abroad, or from public or private research centers.
L'archive ouverte pluridisciplinaire HAL, est destinée au dépôt et à la diffusion de documents scientifiques de niveau recherche, publiés ou non, émanant des établissements d'enseignement et de recherche français ou étrangers, des laboratoires publics ou privés. 


\title{
Geometrical Specification Model for Gear - Expression, Metrology and Analysis
}

\author{
J.Y. Dantan, J. Bruyere ${ }^{1}$, C. Baudouin¹, L. Mathieu² (1), \\ ${ }^{1}$ Laboratoire de Génie Industriel et Production Mécanique - \\ Ecole Nationale Supérieure d'Arts et Métiers, Metz, France \\ ${ }^{2}$ Laboratoire Universitaire de Recherche en Production Automatisée \\ Ecole Normale Supérieure, Cachan, France
}

\begin{abstract}
To ensure the gear precision, industries need a coherent model to express, to analyse and to check geometrical specifications. Most gear tolerance representations are directly driven by the convenience of dimensional metrology and not by the convenience of the set of activities of the tolerancing process.

Therefore, to ensure the coherence of all tolerancing process activities, there is a necessity to develop a complete gear tolerance model which should: represent standard tolerance practices; be integrated in the Computer-Aided systems of design, manufacturing and metrology; be controlled by CMM; and support automated tolerance analysis. The proposed model extends capabilities of a vectorial dimensioning \& tolerancing model in order to satisfy the four requirements. This model is based on GeoSpelling [1]. Its coherence is illustrated by two applications: gear tolerance analysis and gear tolerance verification by CMM.
\end{abstract}

\section{Keywords:}

Tolerancing Model, Functional Metrology, Gear

\section{INTRODUCTION}

As technology increases and performance requirements continually tighten, the cost and required precision of assemblies increase as well. There is a strong need for increased attention to tolerance design to enable highprecision assemblies to be manufactured at lower costs. Indeed, tolerance analysis is a key element in industry for improving product quality.

Designers want tight tolerances to assure product performance; manufacturers prefer loose tolerances to reduce cost. There is a critical need for a quantitative design tool for specifying tolerances. Tolerance analysis brings the engineering design requirements and manufacturing capabilities together in a common model, where the effects of tolerance specifications on both design and manufacturing requirements can be evaluated quantitatively.

The inherent imperfections of manufacturing processes (forging, cutting or grinding) involve geometrical variations and a degradation of product quality. The geometrical variations of each part must be limited by geometrical specifications (tolerances) to ensure a certain level of product quality, which is defined by the functional requirements.

In the case of gears, their geometrical variations impact the transmission error, the tooth contact position, meshing interference, and gap. To ensure a quality level, designers limit these parameters by requirements.

Tolerancing decisions can profoundly impact the quality and cost of gears. To assess the impact of tolerance on gear quality, designers need to simulate the influences of tolerance with respect to the functional requirements. To do so, they use AGMA [2] or ISO tables. These tables are a set of discrete associations between tolerances and meshing quality. They do not take into account all tolerances, and they focus on the pitch error and the misalignment. In the case of a forged gear or not classical gear like WILDHABER-NOVIKOV, designers can not use them to allocate the gear tolerances to achieve the optimal manufacturing cost. This first approach, however, is not very flexible. A second approach is based on experimentations. In order to determine the effects of a tolerance and to understand the contributions of tolerances on a functional requirement, it is necessary to identify the relationships between gear tolerances and functional requirements by a set of experimentations. Effective reuse of experimental knowledge about the effect between gear tolerances and functional requirements is a key strategic component of the gear tolerancing process. This second approach is expensive. There is an important question that requires need to be looked upon: How to determine gear tolerances?

A significant amount of literature is related to tolerance design. It distinguishes four aspects: tolerance representation, tolerance specification, tolerance analysis, and tolerance synthesis [3] (Figure 1). But, few of this research apply to gear.

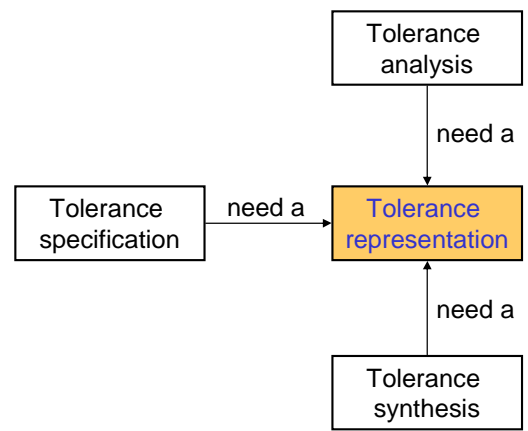

Figure 1: Four aspects and their dependences.

These four aspects are not at the same level, the first one refers to how tolerances are represented internally by the computer, this aspect is indicated directly on the models used for the description of the mechanism without and with geometric variations. Tolerance specification is an important activity for tolerancing. It tries to answer the question: Which tolerance types and 
values are needed on features to control functional requirements? Tolerance analysis is a method to verify the value of functional requirements after tolerances have been specified on each isolated part. This method is totally dependent on the models chosen before. Tolerance synthesis is regarded as a tolerance allocation and a tolerance optimization method taking into account manufacturing and inspection aspects.

The tolerancing process is defined through all the activities involved by geometric product variations management. We can propose four classical activities: tolerance specification, tolerance analysis, tolerance synthesis, and tolerance verification. Tolerance specification, tolerance analysis and tolerance synthesis are sub activities of tolerance design. Tolerance verification defines inspection planning and metrological procedures for functional requirements, functional specifications and manufacturing specifications. It is very important to consider tolerance verification early in the design activities to be able to assess uncertainties. Tolerance verification permits to close the process loop, to check the product conformity and to verify assumptions made by the designer. The tolerancing process depends totally on the models used. The representation of deviations and tolerances, on parts or assembly, is the key problem of tolerancing [1] (Figure 2).

\begin{tabular}{|c|c|c|c|}
\hline $\begin{array}{l}\text { Tolerance } \\
\text { specification }\end{array}$ & $\begin{array}{c}\text { Tolerance } \\
\text { analysis }\end{array}$ & $\begin{array}{l}\text { Tolerance } \\
\text { synthesis }\end{array}$ & $\begin{array}{l}\text { Tolerance } \\
\text { verification }\end{array}$ \\
\hline
\end{tabular}

Tolerance representation / coherent model

Figure 2: Tolerancing process.

To be coherent, the tolerancing process has to use the same language based on a unified mathematical model to express tolerancing for each person involved during the process. To ensure this coherence between gear tolerance design and gear tolerance verification, there is a necessity of developing a complete gear tolerance model which should: (i) represent standard tolerance practices; (ii) be integrated in the Computer-Aided systems of design, manufacturing and metrology, (iii) be controlled by CMM and (iiii) support automated tolerance analysis.

Indeed, most gear tolerance representation schemes are not directly driven by functional requirements, but by the dimensional metrology pratice. In fact, an amount of research has been devoted to the development of Gear Metrology [4].

The paper focuses on the gear tolerance model and its utilization during the tolerancing process. The proposed model extends capabilities of a vectorial dimensioning \& tolerancing model in order to satisfy the four requirements. It is based on GeoSpelling [1] - the model proposed for rebuilding standards [5] in the fields of tolerancing and metrology - GeoSpelling allows to express the specification from the function to the verification with a common language. This model is based on geometrical operations which are applied not only to ideal features, but also to the non-ideal features which represent a real part. These operations are themselves defined by constraints on the form and relative characteristics of the features.

The use of the gear tolerance model for gear tolerance analysis and for gear tolerance verification by CMM illustrates its coherence.

\section{EXPRESSION OF GEOMETRICAL GEAR} SPECIFICATION WITH GEOSPELLING

Obviously, the vast spectrum of gear tolerancing cannot be covered within this paper. Therefore, the following sections will be mainly restricted to the bevel gear and focuses on three types of gear variations which are limited by some tolerances: the flank deviations, the deviations between flanks and the deviations between teeth and hole.

To express these tolerances, we use the classical standardized language and GeoSpelling which is based on the following basic concept:

- a specification is a condition on a characteristic defined from geometric features [1], [5],

- $\quad$ these geometric features are features created from the model of the real surface of the part (SKIN model) by different operations.

A condition defines an interval of IR inside of which the value of a characteristic of geometric features must lie [1], [5].

\section{1 "Profile or form tolerances"}

In the case of the GD\&T standards, the profile deviations are the deviations normal to the transverse involute profiles, measured within the profile evaluation range $L a$ : $F_{\alpha}, f_{f \alpha}, f_{H \alpha},[4]$... These profile characteristics can easily be measured but they are not adapted for tolerance analysis [6]. Therefore, we propose a set of flank form specifications like flank topography [4], [1] (Figure 3). Like $F_{\alpha}, f_{f \alpha}, f_{H \alpha}, \ldots$, we can distinguish different datum systems that define the position and the orientation of the tolerance zone.

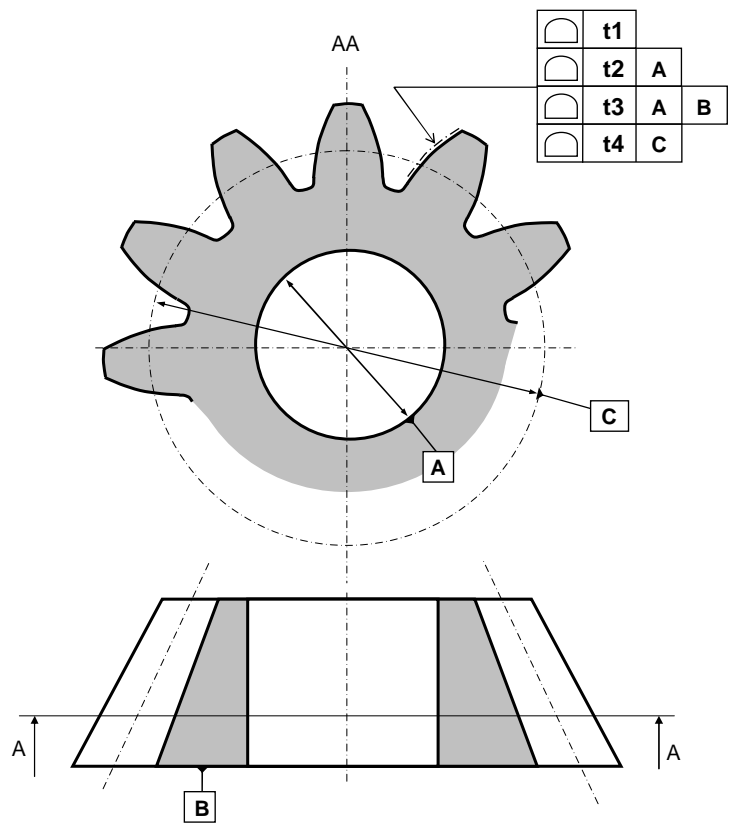

Figure 3: Flank form tolerances.

These specifications of the flank form are defined by a tolerance zone in which this flank must be included. The tolerance zone can be generated according to various methods [7]. The translation of the specification 1 and 2 (Figure 3) in GeoSpelling language is given in Table 1 and Table 2. Let us suppose, Sa and Sf (Figure 4) defined by partition operations [5]. Sa is the non ideal feature [8] which is nominally the cylinder A and Sf the non ideal feature which is nominally a spherical involute, the range of this non ideal feature can be $L_{\alpha}$.

With these four specifications, we can explicitly define the datum system which allows to fit the ideal flank and which locates the tolerance zone. These expressions make easier the tolerance analysis and the tolerance verification. In the case of the conventional profile evaluation, the result requires some rules to interpret deviations correctly. 


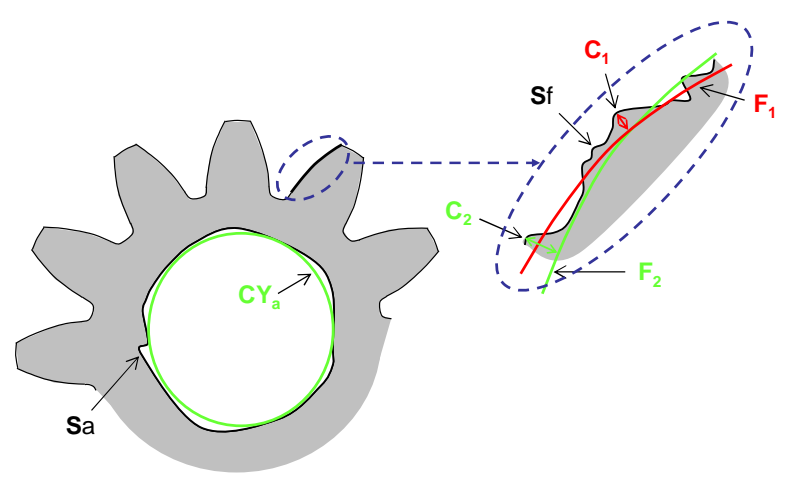

Figure 4: Features and characteristics.

Definition of the associated spherical involute $F_{1}$

Association $\mathrm{F}_{1}$, ideal feature, type spherical involute

Objective to minimize : maximum distance $\left(\mathrm{Sf}, \mathrm{F}_{1}\right)$

Definition of the toleranced characteristic $\mathrm{C}_{1}$

Evaluation $\mathrm{C}_{1}$ : maximum distance $\left(\mathrm{Sf}, \mathrm{F}_{1}\right)$

Definition of the condition

$\mathrm{C}_{1} \leq \mathrm{t}_{1} / 2$

Table 1: GeoSpelling expression of specification 1.

Definition of the datum A

Association $\mathrm{CYa}$, ideal feature, type Cylinder

Constraints: minimum signed distance $(\mathrm{Sa}, \mathrm{CYa}) \geq 0$

Objective to maximize : diameter of CYa

Definition of the associated spherical involute $F_{2}$

Association $\mathrm{F}_{2}$, ideal feature, type spherical involute

Constraints: coaxiality between $\mathrm{CYa}$ and axis of $\mathrm{F}_{2}$

Objective to minimize : maximum distance $\left(\mathrm{Sf}, \mathrm{F}_{2}\right)$

Definition of the toleranced characteristic $\mathrm{C}_{2}$

Evaluation $\mathrm{C}_{2}$ : maximum distance $\left(\mathrm{Sf}, \mathrm{F}_{2}\right)$

Definition of the condition

$\mathrm{C}_{2} \leq \mathrm{t}_{2} / 2$

Table 2: GeoSpelling expression of specification 2.

\section{2 "Pitch tolerances" and "Runout tolerances"}

In the same way, we can express some specifications which limit the cumulative angular pitch deviation (orientation deviations between flanks) and the runout (situation deviations between teeth and hole).

In the case of the standard [2], the cumulative pitch deviation Fpk over a sector of $k$ pitches is the algebraic difference between the actual length and the theoretical length of the relevant arc. Bevel gears are being tested close to the mean pitch cone diameter $d_{M}$ [4], but the datum in which $d_{M}$ is defined is not clarified.

Therefore, we propose to limit the cumulative angular pitch deviation which is the difference between the nominal angle between two flanks and the angle [8] around a datum axis between two associated flanks. The two associated flanks are defined by association operations [1] with constraints: coaxiality between the datum axis and the axis of the involute cone. The datum axis can be the axis of the associated hole or the associated teeth cone (Figure 5).

In the case of the standard, the runout of teeth [4], Fr, is the total variation of the distance between a datum surface(s) (hole) and an indicated surface(s) (teeth). Typical runout types are axial and radial. Runout of a bevel gear is caused by the superposition of different deviations. Therefore, the runout tolerance analysis is complex.

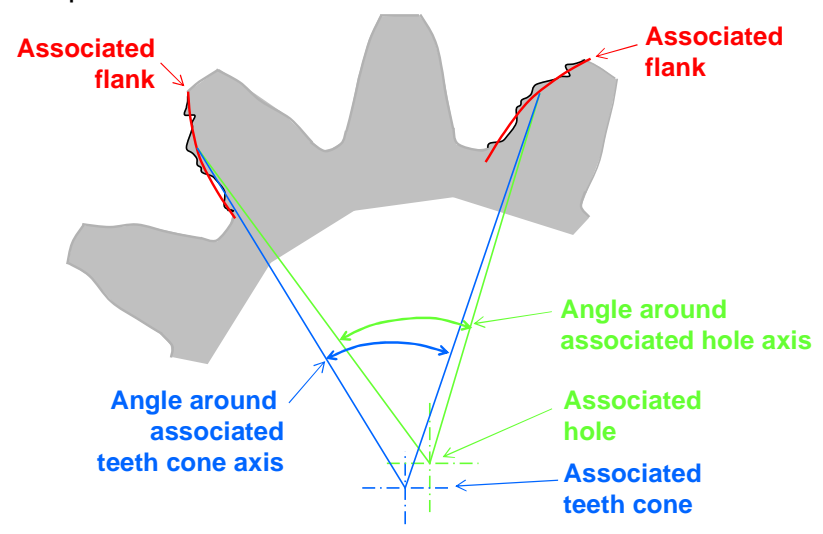

Figure 5: Pitch deviations.

We propose to dissociate the cause of the runout and to limit the situation deviations [5] between the associated hole and the associated teeth cone (Figure 6).

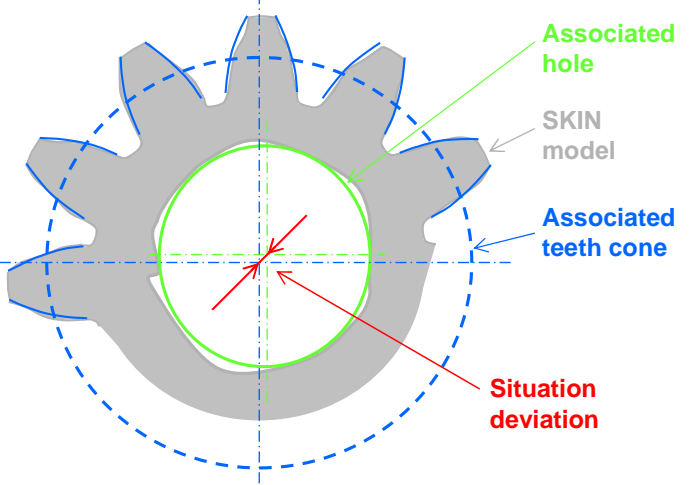

Figure 6: Runout deviation.

For the functional tolerancing, we advocate to consider the form tolerance (specification 1 - Figure 3), the form position tolerances with the hole datum system (specifications 2 and 3 - Figure 3) and the pitch tolerance around the hole datum axis; because the gear revolves around of the hole axis.

For the manufacturing tolerancing, we advocate to consideration the form tolerance (specification 1 - Figure 3 ), the form position tolerance with the teeth datum system (specification 4 - Figure 3 ), the pitch tolerance around the teeth datum axis and the runout deviation; because we can dissociate the cumulative pitch angular error around the teeth cone axis and the deviations between the teeth cone axis and the hole axis. This dissociation is interesting for the simulation of the impact of forging and machining variations, because the cumulative pitch angular errors around the teeth cone axis are due to the forging operation and the deviation between the teeth cone axis and the hole axis are due to the machining operation.

\section{A COHERENT TOLERANCING PROCESS}

To illustrate the coherence of this proposed geometrical specification model, two examples are shown: Tolerance analysis and tolerance verification by CMM.

\subsection{Gear Tolerance analysis}

This example is based on:

- an analytical definition (parametric model) of tooth surface in a global coordinate system which includes form deviations, location and orientation deviations between features and gaps, 
- a mathematical representation of the geometrical specifications which are detailed in section 2 ,

- a digital simulation tool based on Tooth Contact Analysis [9] which enables one to evaluate functional characteristics as kinematic error, position of contact point, , ... (the result is similar to the tangential composite test [6], but the cost of a digital simulation is lower than the cost of an experimental simulation),

- a tolerance analysis tool by Monte Carlo simulation, which computes the probability that the product can be assembled and will function (respect of requirements on the kinematic error, ...) for given individual tolerances.

The result of a statistical tolerance analysis [6] is a set of meshing simulations (Figure 7), the probability distribution of each functional characteristics like kinematic error (Figure 8).

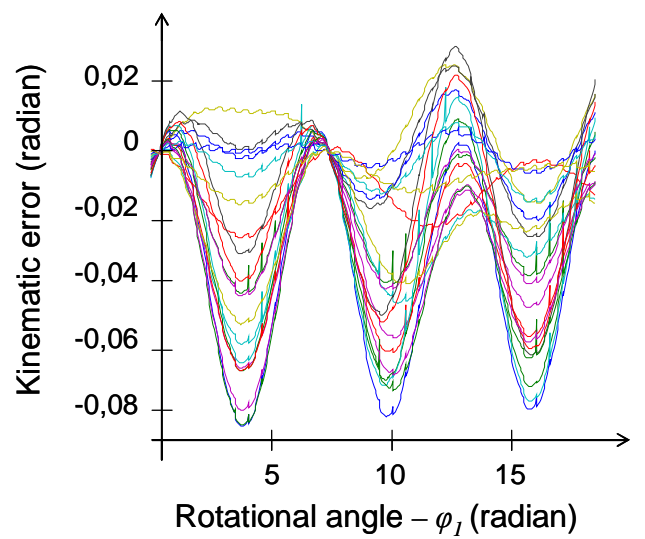

Figure 7: Numerical meshing simulations

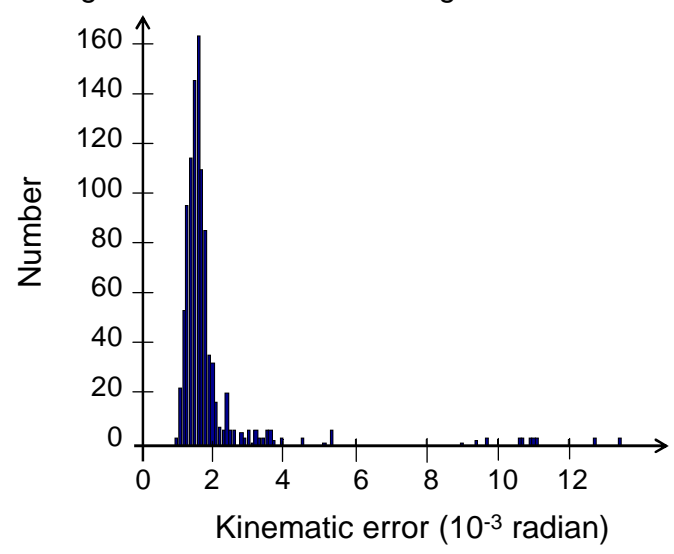

Figure 8: Tolerance analysis

\subsection{Gear Tolerance verification.}

Tolerance verification permits one to check the product conformity and to verify assumptions made by the designer. To do so, we develop some metrological procedures for adequacy with the GeoSpelling [5] expression of each geometrical specification which is detailed in section 2 .

Section 2.2 explains the importance of the definition of a datum axis to specify the cumulative angular pitch deviation. To illustrate this, we evaluate the circular thickness around two datum systems: the datum system based on the teeth (Figure 5) and the datum system based on the hole (Figure 5), we can determine the difference of the values according to the datum systems (Figure 9). In fact, we can dissociate the impact of the cumulative pitch angular error around the teeth cone axis and the situation deviations between the teeth cone axis and the hole axis.

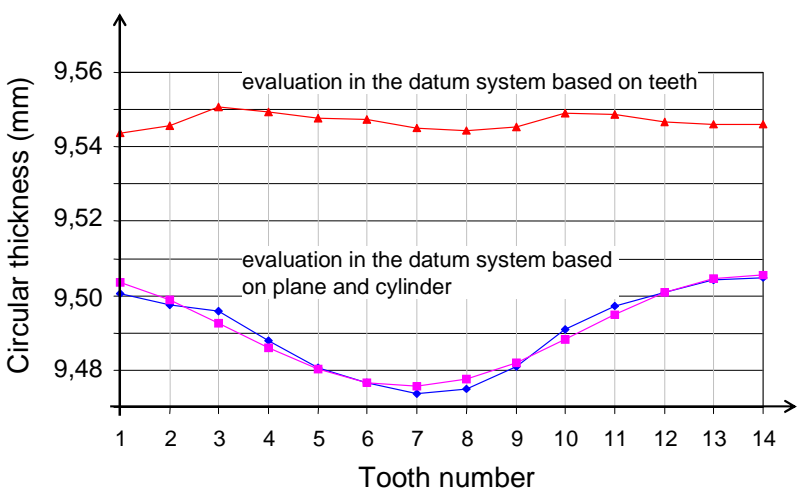

Figure 9: Influence of the datum system on pitch deviations.

\section{CONCLUSION}

The important point of the proposed geometrical specification model for a gear based on GeoSpelling is to provide an unique solution to express tolerances based on geometry. This way is based on the characteristic concept. Taken into account directly, in the expression of the specification, the result based on a mathematical expression is unique and clearly described for everybody. There is no more interpretation for the designer, the manufacturer and the metrologist.

Indeed, tolerance analysis or tolerance verification are based on tolerance representation. Given a particular tolerance representation, efficient and accurate algorithms are needed to actually perform the tolerance analysis. Unfortunately, as the geometric tolerances are complex, so too are the algorithms using these tolerances.

For managing efficiently geometrical variations along the product life cycle, we propose a geometrical specification model for gears based on GeoSpelling which is the basis of a complete and coherent tolerancing process.

\section{REFERENCES}

[1] Mathieu L. and Ballu A, 2003, GeoSpelling: a common language for Specification and Verification to express Method Uncertainty, Proc. of 8th CIRP Seminar on Computer Aided Tolerancing, North Carolina, USA.

[2] ANSI/AGMA 2009-B01, 2005, Bevel Gear Classification, Tolerances, and Measuring Methods.

[3] Salomons O., Van Houten F., Kals H., 1998, Current Status of CAT Systems, Geometric Design Tolerancing: Theories, Standards and Applications, pp. 438-452, ISBN 0-412-83000-0.

[4] Goch G., 2003, Gear Metrology, Annals of CIRP, 52/2:659-695.

[5] ISO/TS 17450-1, 2005, Geometric Product Specification (GPS) - General concepts - Part 1: Model for geometrical specification and verification.

[6] Bruyere J., Dantan J.Y., Bigot R., Martin P., 2006, Statistical tolerance analysis of bevel gear by Tooth Contact Analysis and Monte Carlo simulation, in press, Mechanism and Machine Theory.

[7] Pasupathy T., Zhao X., Wilhelm R., 2006, Flexible tools for specifying design variation, Int. J. Adv. Manufacturing Technology, 28:659-664.

[8] Ballu A., Mathieu L., Dantan J.Y., 2001, Global view of geometrical specifications, Proc. of 7th CIRP Seminar on Computer Aided Tolerancing, Cachan, France.

[9] Litvin F.L., 2004, Gear Geometry and Applied Theory, PTR Prentice Hall, Englewood Cliffs, NJ. 